\title{
Direito Constitucional Luso e Brasileiro na Contemporaneidade, Pedro Trovão do Rosário, Luciene Dal Ri e Denise Hammerschmidt (coords.). Curitiba: Juruá, 2019, ISBN 978-853-628-552-8
}

\section{ALEX SANDER XAVIER PIRES*}

asxpires@gmail.com

GALILEU - REVISTA DE DIREITO E ECONOMIA * e-ISSN 2184-1845

Volume XX $\cdot 1^{\text {st }}$ January Janeiro $-30^{\text {TH }}$ June Junho $2019 \cdot$ pp. 159-163

DOI: ???

A obra coletiva, Direito Constitucional Luso e Brasileiro na Contemporaneidade, coordenada pelos Professores Doutores Luciene Dal Ri, Pedro Trovão do Rosário e Denise Hammerschmidt, é fruto da contribuição de dezessete co-autores em representação de dezoito conceituadas universidades das quais efluíram seis Programas de Doutoramento, portugueses (Universidade Autónoma de Lisboa e Universidade de Coimbra) e brasileiros (Universidade Estadual do Norte do Paraná, Centro Universitário Guanambi, Universidade Federal de Santa Catarina, e Universidade do Vale do Itajaí), e dois Centros de Investigação em Direito, o Ratio Legis/UAL e UNIVALI/SC com a participação do Centro Universitário Católica de Santa Catarina.

Para além das relações interinstitucionais que devem orbitar a produção acadêmico-científica em nível de qualidade e excelência das investigações, a obra teve uma importância maior ao pôr em causa a estabilidade do Direito Constitucional, em
Portugal e no Brasil, em tempos de reconstrução de institutos e teorias diante dos novos fenômenos econômicos, sociais, políticos, e jurídicos trazidos pelo alinhamento das relações humanas imposto pela derrocada das fronteiras físicas em prol da concepção de uma "aldeia global".

A iniciar pelo Prefácio, o Doutor Carlos Ayres Britto e a Mestranda Nara Ayres de Britto, sistematizam a Constituição da República Federativa do Brasil de 1988 sob a leitura da democracia enquanto princípio supremo em constante reconstrução ao longo dos trinta anos de vigência da atual ordem constitucional brasileira.

O Professor Doutor Pedro Trovão do Rosário, no texto "Constitucionalismos e democracias um paradoxo?", analisa o referendo constitucional no âmbito da tensão entre o constitucionalismo e a democracia numa relação moderada pelo princípio da soberania popular concebido em três vertentes: a titularidade do poder político em nome do povo, a Constituição como 
instrumento de desvelamento da vontade popular, por um lado, e como norma determinante da forma de escolha dos representantes, por outro.

O Professor Doutor Jónatas E. M. Machado, no texto "O princípio anticorrupção na Constituição brasileira de 1988 - a corrupção como inimigo número um", ao reconhecer a matriz constitucional do princípio anticorrupção posto ao lado dos princípios do respeito pelos direitos fundamentais, da república, da democracia, da separação de poderes, e do estado de direito, discute as inúmeras possibilidades de sua aplicação restritas a contenção da corrupção enquanto vilã da ordem constitucional por obstar a proteção do bem comum e o acesso aos direitos e interesses prometidos constitucionalmente à população.

O Professor Doutor Alex Sander Xavier Pires, no texto "Ativismo judicial e judicialização da política: contributo propositivo no âmbito dos trinta anos da Constituição Federal do Brasil", sistematiza a mudança do paradigma atuário do Poder Judiciário no âmbito das constituições democráticas do pós-guerras mundiais que experimentaram a inversão da justificação da soberania a passar, em grau de prevalência, da nacional para a popular cuja evidência no dever público de garantia de acesso a direitos constitucionais desafiou uma maior atuação dos órgãos jurisdicionais o que deflagrou o fenômeno do ativismo judicial, num primeiro momento, e da judicialização da política, em seguida.
A Professora Doutora Luciene Dal Ri, no texto "A recepção do costume em Direito Internacional entre Portugal e Brasil: característica de um constitucionalismo lusófono?", põe em causa a recepção do costume internacional enquanto traço característico de um constitucionalismo lusófono unidirecional, para ponderar sobre a existência de "caminhos de divergência" entre os sistemas jurídicos que admitem, ao menos, um "certo diálogo".

O Doutorando Luiz Carlos Avila Junior, no texto "Constituição material e a mutação pelos costumes de natureza constitucional", demonstra que a realidade social é o que move as constituições tidas por materiais num ambiente de preceitos axiológicos e/ou metaéticos concebidos numa perspectiva de dignidade da pessoa humana, de sorte que os "costumes de natureza constitucional" ganham importância no contexto da mutação constitucional.

O Doutorando Carlos Eduardo Figueiredo, no texto "A crise do Estado Democrático e a gestão dos supérfluos", debate a instabilidade institucional dos Estados Democráticos à luz da globalização, da formação de uma nova "classe de indesejáveis" e da formação de um modelo atuarial de matriz criminal que leva ao encarceramento em massa.

O Doutorando Fernando de Paula G. Ferreira, no texto "O princípio anticorrupção como proteção dos direitos fundamentais no Brasil e em Portugal - um ensaio sobre a dignidade da pessoa humana", 
numa leitura jusfilosófica traz à discussão o fenômeno da corrupção institucionalizada, no Brasil e em Portugal, enquanto elemento impeditivo a plena satisfação da dignidade humana, em que o princípio antitético da anticorrupção serviria de elemento de contenção aos desvios de conduta.

A Professora Doutora Denise Hammerschmidt, no texto "Emprego de métodos de identificação criminal por perfis genéticos de suspeitos e criminosos no modelo constitucional brasileiro e português, em face dos direitos fundamentais e da judicialização da política", apresenta elementos para demonstrar a eventual compatibilidade constitucional especialmente com os princípios da dignidade humana, a presunção de inocência, a liberdade a não-autoincriminação, e o direito da intimidade genética, do Banco de Dados de Perfis Genéticos.

O Professor Doutor Claudio Carneiro, no texto "A jurisprudência de crise e justiça social perante as cortes constitucionais do Brasil e de Portugal", demonstra a importância da fixação das matrizes teórico-argumentativas das decisões de um tribunal constitucional no sentido de preservar a segurança jurídica e garantir a estabilidade constitucional em momentos de crise - especialmente a econômico-financeira -, no sentido de concretização dos direitos fundamentais.

O Professor Doutor Gustavo Swain Kfouri, no texto "A possível superação do modelo liberal de representação política através da realização do modelo do Estado de Partidos no Brasil", põe em causa a representatividade democrática por partidos políticos pelo viés personalista dos mandatários eleitos sugerindo a reconfiguração da Democracia Partidária à luz do modelo de Estado de Partidos.

O Professor Doutor J. S. Fagundes Cunha e a Professora Doutora Erika Zanoni, no texto "Ensaios de uma cosmovisão teleológica para elaboração de uma legislação específica da TAA (Terapia Assistida por Animais)", apresentam o modelo de terapia assistida por animais ponderando sobre a necessidade de regulamentação específica sobre o tema que inclua a proteção dos animais em nível de estresse, angústia e medo, bem como a prestação de informações em nível sanitário e de zoonoses.

O Professor Doutor Gilberto Giacoia, no texto "Vida, na visão da Constituição e dos Direitos Fundamentais", reflete sobre a existência do ser no âmbito da sempre tensa leitura entre vida e morte, o que sugere seja invertido o paradigma de análise da fundamentação meramente social da existência da ordem jurídica para acepção da vida em sociedade articulada pela ideia de justiça num âmbito multidisciplinar entre os métodos jurídico, teológico e filosófico, tendo na dignidade humana a moderação do discurso.

A Professora Doutora Viviane Bortolini Giacomazzi, no texto "Cidadania e o reco- 
nhecimento de minorias étnico-sociais: sob perspectiva das cortes constitucionais", questiona a eficácia voluntária dos direitos fundamentais quanto a função de inclusão das minorias ético-sociais à luz da efetivação da ideologia de universalização dos direitos humanos; e, pondera, em contraposição, se a dita eficácia somente seria possível por atuação direta das cortes constitucionais, em especial o Supremo Tribunal Federal do Brasil.

A Professora Mestra Roseli de Fátima Bialeski Bozza e o Professor Doutor Fábio da Silva Bozza, no texto "O Direito Humano fundamental ao desenvolvimento no contexto da globalização econômica", ponderam a necessidade do direito fundamental ao desenvolvimento, na era da globalização econômica, ser lido pelo viés social em primazia ao viés econômico, o que desvelaria a necessidade de se assentar um constitucionalismo cosmopolita que favorecesse a promoção dos direitos humanos fundamentais, no sentido de favorecimento do diálogo entre as normas internacionais de direitos humanos e as normas constitucionais internas de cada país.

O Professor Doutor Tarcisio Germano de Lemos Filho, no texto "A circulação de decisões estrangeiras, a partir do Código de Processo Civil brasileiro de 2015. A experiência portuguesa e europeia como paradigma ao aperfeiçoamento do modelo nacional", analisa, à luz da ordem processual civil incluída em 2015, a inovações procedimentais e a mudança do paradigma atuário jurisdicional sobre a efetividade das sentenças judiciais entre Estados soberanos distintos e em respeito à cooperação internacional, o que o faz em atenção aos modelos português e da União Europeia.

A Professora Doutora Maria Goretti dal Bosco e a Professora Doutora Carla Liliane Waldow Esquivel, no texto "Direito Humano à água: políticas públicas e garantia de alimentação adequada no Brasil", analisam o tratamento dispensado à água na seara dos direitos humanos com repercussão no direito do indivíduo a tê-la no âmbito da alimentação adequada, especialmente no tratamento dado pelo governo brasileiro àqueles de menor poder aquisitivo.

A Professora Doutora Érika Louise Bastos Calazans, no texto "Uma análise comparada sobre a titularidade dos direitos e deveres fundamentais dos migrantes na Constituição Brasileira e Portuguesa e seus reflexos na legislação de migração", propõe a análise comparativa entre os direitos e garantias fundamentais previstos nos ordenamentos jurídicos brasileiro e português, quanto às disposiç̧ões normativas e a leitura principiológica destinadas à migração, o que o faz partindo da visão constitucional de cada Estado para, em seguida, adentrar a legislação específica.

Ao término da leitura, o atento leitor percebe que os autores, longe de proporem verdades, trazem ao debate fenômenos da contemporaneidade com nítido interesse científico e acadêmico para o Direito Cons- 
titucional, tanto português como brasileiro, de sorte que incumbe, a cada um de nós, construtores das ordens, jurídica, social, política e econômica, o dever de ponderar os argumentos e construirmos uma ordem constitucional hábil a garantir o acesso aos direitos constitucionais de uma forma mais eficaz e equânime, especialmente os direitos fundamentais.

Agradece-se, assim, os autores pela oportunidade de reflexão e ponderação de fenômenos tão caros a contemporaneidade que exigem ser debatidos e esclarecidos, o que se lhes faz nominalmente: Carlos Ayres Britto, Nara Ayres de Britto, Pedro Trovão do Rosário, Jónatas E. M. Machado, Alex Sander Xavier Pires, Luciene Dal Ri, Luiz
Carlos Avila Junior, Carlos Eduardo Figueiredo, Fernando de Paula G. Ferreira, Denise Hammerschmidt, Claudio Carneiro, Gustavo Swain Kfouri, J. S. Fagundes Cunha, Erika Zanoni, Gilberto Giacoia, Viviane Bortolini Giacomazzi, Roseli de Fátima Bialeski Bozza, Fábio da Silva Bozza, Tarcisio Germano de Lemos Filho, Maria Goretti dal Bosco, Carla Liliane Waldow Esquivel, e Érika Louise Bastos Calazans.

\footnotetext{
* Pós-Doutor em Direito (Portugal), Doutor em Ciências Jurídicas e Sociais (Argentina), Doutor em Ciência Política (Brasil). Fundador do Projeto Pensar a Justiça. Professor universitário - Universidade Autónoma de Lisboa (UAL). Investigador no Centro de Investigação Ratio Legis/UAL. Secretário-Geral do ECII - Ethical \& Compliance International Institute. Colaborador no Centro de Investigação CEDIS/UNL. Advogado.
} 